\title{
The Combined Effect of Chemical Reaction, Radiation on Heat and Mass Transfer along a Continuously Moving Surface in Presence of Thermophoresis
}

\author{
B. Chandra ${ }^{1 \dagger}$ and M. Kumar ${ }^{1}$ \\ ${ }^{1}$ Department of Mathematics, Statistics and Computer Science College of Basic Sciences \& Humanities \\ G. B. Pant University of Agriculture \& Technology Pantnagar -263145, Uttarakhand India
}

$\dagger$ Corresponding Author Email: bhaskerchandra6@gmail.com

(Received September 14, 2011; accepted July 21, 2012)

\begin{abstract}
The effect of chemical reaction, radiation on heat and mass transfer along a continuously moving surface in presence of thermophoresis has been discussed. The fluid viscosity is assumed as an inverse linear function of temperature. The system of non-linear partial differential equations developed in the process have finally transformed into a set of ordinary differential equations with the help of similarity transformation and then solved numerically using RungaKutta method with shooting technique. The results showing the effect of physical parameters on velocity, temperature and concentration have been computed and presented graphically to discuss them in detail. It has been observed that temperature increases with an increase in radiation parameter. Also, it is seen that the concentration decreases with the increase in chemical reaction parameter and Schmidt number.
\end{abstract}

Keywords: Chemical reaction, Continuously moving surface, Heat \& mass transfer, Thermophoresis, Radiation.

\section{INTRODUCTION}

The application of MHD incompressible viscous flow involving heat and mass transfer under the influence of chemical reaction is of great importance to many areas of science and engineering. This frequently occurs in crystal growing, paper production,metal extrusion, agricultural and petroleum industry etc. In many chemical engineering processes, chemical reactions take place between a foreign mass and the working fluid.

Sakiadis (1961) considered theboundary layer behavior on continuous moving solid surfaces. Erickson et al. (1966) studied the heat and mass transfer on a moving continuous flat plate with suction or injection. Tsou et al. (1967) studied flow and heat transfer in the boundary layer on a continuously moving surface whereas Soundalgekar and Murty (1980) studied the heat transfer problem by assuming the plate temperature to be variable. Pop et al. (1992) obtained similarity solution for viscosity varies as an inverse function of temperature and assuming constant velocity and temperature of the plate. Howell et al. (1997) have studied the momentum and heat transfer on a continuous moving surface in a power law fluid. Kumari and Nath (2001) discussed the problem of MHD boundary layer flow of a non-Newtonian fluid over a continuously moving surface with a parallel free stream. Fang (2003) studied the similarity solution of thermal boundary layer for a moving flat plate.Makinde and Ogulu (2008) studied the effect of thermal radiation on the heat and mass transferflow of a variable viscosity fluid past a vertical porous plate permeated by a transverse magnetic field. Recently Jat and Chaudhary (2010) presented hydromagnetic flow and heat transfer on a continuously moving surface. The mass transfer with chemical reaction study will be mile stone to investigation in such problems. Thermophoresis and radiation will definitely enhance the potential of the research in the field. So present investigation deals with the combined effect of chemical reaction, radiation on heat and mass transfer along a continuously moving surface in presence of thermophoresis.

\section{FORMULATION}

Consider the two-dimensional steady flow of an electrically conducting, viscous, incompressible fluid past a continuously moving surface with uniform velocity (U) in the presence of magnetic field of strength $B_{0}$ and thermophoresis. In addition to these effects, presence of chemical reaction and radiation have also been considered. The induced magnetic field is neglected. The $\mathrm{x}$-axis is taken along the surface and 
y-axis normal to it. $B_{0}$ is working along y -axis. The fluid viscosity which is assumed to be an inverse linear function of temperature, Lai and Kulacki (1991) has given it as:

$$
\begin{aligned}
& \frac{1}{\mu}=\frac{1}{\mu_{\infty}}\left[1+\gamma\left(T-T_{\infty}\right)\right] \\
& \frac{1}{\mu}=a\left(T-T_{r}\right)
\end{aligned}
$$

Where

$$
a=\gamma / \mu_{\infty}, T_{r}=T_{\infty}-1 / \gamma
$$

The $\mu$ is the coefficient of viscosity, $\mu_{\infty}$ is reference viscosity, $\gamma$ is a constant, $\mathrm{T}$ and $T_{\infty}$ are the temperature of the fluid near and far away from the moving surface. $\mathrm{T}_{\mathrm{r}}$ and $\mathrm{a}$ are constants. In general, $\mathrm{a}>0$ for liquids and $\mathrm{a}<0$ for gases. The boundary layer equations governing the flow and heat and mass transfer due to a continuously moving surface are:

Equation of continuity:

$\frac{\partial u}{\partial x}+\frac{\partial v}{\partial y}=0$

Equation of momentum:

$$
\rho\left(u \frac{\partial u}{\partial x}+v \frac{\partial v}{\partial y}\right)=\frac{1}{\rho} \frac{\partial}{\partial y}\left(\mu \frac{\partial u}{\partial y}\right)-\frac{\sigma_{e} B_{0}^{2} u}{\rho}
$$

Equation of energy:

$$
\begin{aligned}
u \frac{\partial T}{\partial x}+v \frac{\partial T}{\partial y}= & \frac{k}{\rho C_{p}} \frac{\partial^{2} T}{\partial y^{2}}+\frac{\mu}{\rho C_{p}}\left(\frac{\partial u}{\partial y}\right)^{2}-\frac{1}{\rho C_{p}} \frac{\partial q_{r}}{\partial y} \\
& +\frac{\sigma_{e} B_{0}^{2} u^{2}}{\rho C_{p}}
\end{aligned}
$$

Equation of diffusion:

$$
\begin{aligned}
u \frac{\partial C}{\partial x}+v \frac{\partial C}{\partial y}= & D \frac{\partial^{2} C}{\partial y^{2}}-k_{l}\left(C-C_{\infty}\right) \\
& -\frac{\partial}{\partial y}\left(V_{T}\left(C-C_{\infty}\right)\right)
\end{aligned}
$$

where $\rho$ be the density, $\sigma_{e}$ the electrical conductivity, $\mathrm{k}$ is thermal conductivity of the fluid, $C_{p}$ the specific heat at constant pressure, $K_{1}$ is chemical reaction parameter, $V_{T}$ is thermophoretic velocity, $\mathrm{D}$ is mass diffusivity and other symbols have their usual meanings.

The radioactive heat flux $q_{r}$ under Rosseland approximation by Brewster (1992) has the form: $q_{r}=-\frac{4 \sigma_{1} \partial T^{4}}{3 \alpha \partial y}$

Where $\sigma_{1}$ is Stefan-Boltzmann constant and $\alpha$ is the mean absorption coefficient. We assume that the temperature differences within the flow are so small that $T^{4}$ can be expressed as a linear function of $T_{\infty}$.

This is obtained by expending $T^{4}$ in Taylor series about $T_{\infty}$ and neglecting the higher order terms. Thus we get:

$T^{4}=4 T_{\infty}^{3} T-3 T_{\infty}^{4}$

The corresponding boundary conditions are:

$u=U, v=0, T=T_{w}, C=C_{w}$ at $y=0$

$u=0, T \rightarrow T_{\infty}, C \rightarrow C_{\infty} \quad$ as $y \rightarrow \infty$

Stream function $\Psi(x, y)$ satisfies equation of continuity and $\mathrm{u}$ and $\mathrm{v}$ are given by:

$u=\frac{\partial \Psi}{\partial y}, v=-\frac{\partial \Psi}{\partial x}$

The momentum, energy and concentration Eqs. (5), (6) and (7) can be transformed into the corresponding ordinary differential equations by introducing the following similarity transformations.

$\Psi=\sqrt{U x v_{\infty}} f(\eta)$

$\eta=y \sqrt{U / v_{\infty} x}$

$\theta(\eta)=\left(T-T_{\infty}\right) /\left(T_{w}-T_{\infty}\right)$

$\varnothing(\eta)=\left(C-C_{\infty}\right) /\left(C_{w}-C_{\infty}\right)$

Where $v_{\infty}$ is a reference kinematic viscosity. It will be assumed that the temperature difference between the moving surface and the free stream varies as $A x^{n}$ i.e.

$T_{w}(x)-T_{\infty}=A x^{n}$

Where $\mathrm{A}$ is a constant, $\mathrm{n}$ is exponent and $\mathrm{x}$ is measured from the leading edge of the surface. The momentum, energy and concentration Eqs. (5)-(7) finally reduced to the following forms:

$$
\begin{aligned}
& f^{\prime \prime \prime}-\left(1 / \theta-\theta_{r}\right) \theta^{\prime} f^{\prime \prime}-\left(\begin{array}{r}
\theta-\theta_{r} \\
/ 2 \theta_{r}
\end{array}\right) f f^{\prime \prime} \\
& +\operatorname{Re}_{m}^{2}\left(\theta-\theta_{r} / \theta_{r}\right) f^{\prime}=0
\end{aligned}
$$




$$
\begin{aligned}
& \theta^{\prime \prime}-n \operatorname{Pr} f^{\prime} \theta+(\operatorname{Pr} / 2) f \theta^{\prime}-\operatorname{Pr} E c \\
& \left(\theta_{r} / \theta-\theta_{r}\right) f^{\prime 2}+\operatorname{Re}_{m}^{2} \operatorname{Pr} E c f^{\prime 2}+R \theta^{\prime \prime}(\eta)=0 \\
& \varnothing^{\prime \prime}+(S c / 2) f \varnothing^{\prime}-K c S c \varnothing-\tau S c \theta^{\prime \prime} \varnothing-\tau S c \theta^{\prime} \varnothing^{\prime}=0
\end{aligned}
$$

The corresponding boundary conditions are:

$$
\begin{aligned}
& f=0, f^{\prime}=1, \theta=1, \varnothing=1 \text { at } \eta=0 \\
& f^{\prime} \rightarrow 0, \theta \rightarrow 0, \varnothing \rightarrow 0 \quad \text { at } \eta \rightarrow \infty
\end{aligned}
$$

Where the prime (') denotes differentiation with respect to $\eta$ and symbols are defined as:

$$
\begin{aligned}
& R={ }^{16 \sigma_{1}} T_{\infty}^{3} / 3 \alpha k \text { (radiation parameter) } \\
& S c=v / D(\text { Schmidt number }) \\
& \operatorname{Pr}=\mu C_{P} / k(\operatorname{Pr} \text { andtl number }) \\
& \tau=\frac{k\left(T_{W}-T_{\infty}\right)}{T_{\infty}}(\text { thermophoretic parameter }) \\
& K c=-k_{1} x / U^{(\text {Chemical reaction parameter })} \\
& \operatorname{Re}_{m}=B_{0} \sqrt{\sigma_{e} x / \rho U}(\text { Magnetic parameter }) \\
& E c=U^{2} / C_{p}\left(T_{W}-T_{\infty}\right)(E c \text { ker } t \text { number })
\end{aligned}
$$

The Eqs. (14),(15) and (16) constitute a non-linear coupled boundary value problem prescribed at two boundaries, the analytical solution of which is not feasible. Therefore, these equations have been solved numerically on computer using Newton's shooting techniques with the fourth-order Runge-Kutta integration scheme. The corresponding velocity, temperature and concentration profiles are shown in Fig. 1 to 13 .

\section{Result ANd Discussion}

The Prandtl number physically correspond to liquid metals for its value $<<1$, di-atomic gases for $\sim 1$ and high-viscosity oils for $>>1$. Figure 1 shows the velocity profile for varying magnetic parameter $(\mathrm{Rem}=0,0.3,1$ ) It is noticed that magnetic parameter shows adverse effect on velocity i.e. on increasing magnetic parameter the magnitude of velocity decreases. Figure 2 depicts the effect of dimensionless reference temperature on velocity profile and it has been seen that velocity decreases with its increasing values for temperature $(\theta r=2,4,15)$. It is seen from Fig. 3 that velocity decreases on increasing Prandtl number $(\operatorname{Pr}=0.1,1,3)$. Figure 4 depicts the effect of radiation parameter on temperature profile. It is seen that the temperature increases with an increase in radiation parameter $(\mathrm{R}=$ $0,1,10)$.It is also seen that in Fig. 5 the temperature decreases with increasing exponent $(n=1,2,3)$. Figure 6 represents the effect of Prandtl number on temperature and observed that it decreases with increasing values of Prandtl number $(\operatorname{Pr}=0.1,1,3)$. The computations for effect of magnetic parameter on temperature profile were also made and depicted in Fig. 7. It is found that temperature increases with magnetic parameter $\left(\operatorname{Re}_{\mathrm{m}}=0,0.3,1\right)$. It is also seen that the temperature increases with an increase in Eckert number radiation $(\mathrm{Ec}=1,3,5)$ as presented in Fig. 8.

The study of the effect of thermophoretic parameter on concentration has also been done. It is seen that the concentration decreases with an increase in thermophoretic parameter $(\tau=0,0.5,1)$ as depicted in Fig. 9.The effect of Prandtl number on concentration is illustrated in Fig. 10. It is seen that the concentration decreases with increasing Prandtl number $(\operatorname{Pr}=0.1,1$, 3). It is also seen that in Fig. 11 the concentration increases as magnetic parameter increases $\left(\operatorname{Re}_{\mathrm{m}}=0,0.3,1\right)$. It is noticed that the concentration decreases as Schmidt number increases $(\mathrm{Sc}=0,0.5,1)$ as in Fig. 12. The effect of chemical reaction on concentration is illustrated in Fig. 13. It indicates that concentration decreases with increasing values of chemical reaction parameter $(\mathrm{Kc}=0,0.2,0.6)$.

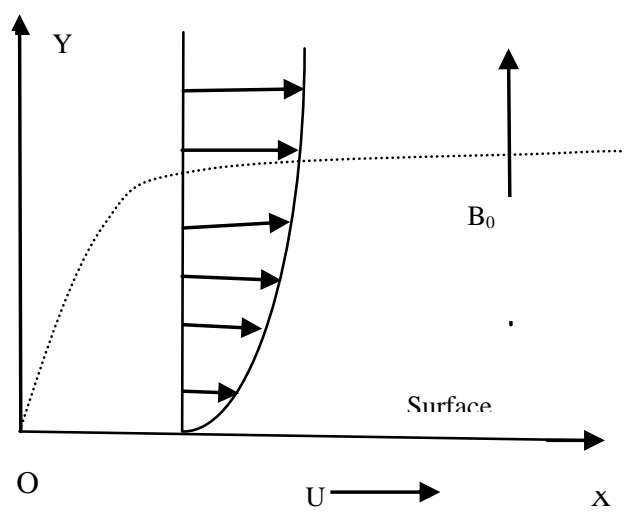

Physical model

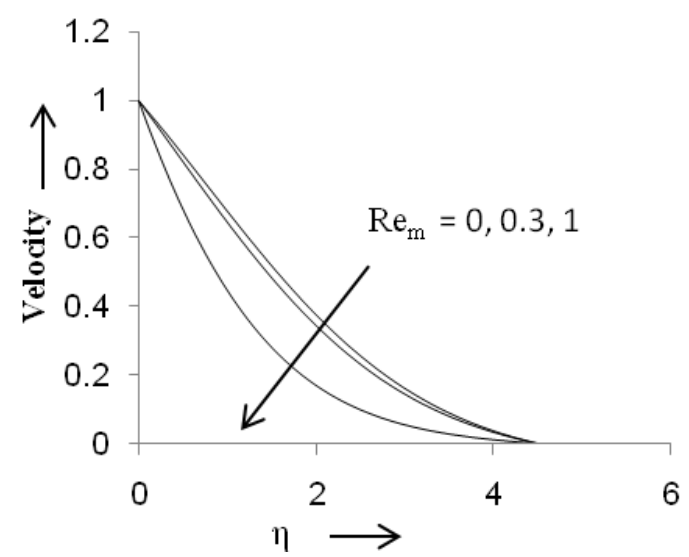

Fig. 1.Velocity profile with $\operatorname{Re}_{\mathrm{m}}$ for $\mathrm{R}=1, \operatorname{Pr}=0.1, \tau=0.5$, $\mathrm{Sc}=0.5, \mathrm{Ec}=1, \mathrm{n}=1, \theta_{\mathrm{r}}=2, \mathrm{Kc}=0.2$ 


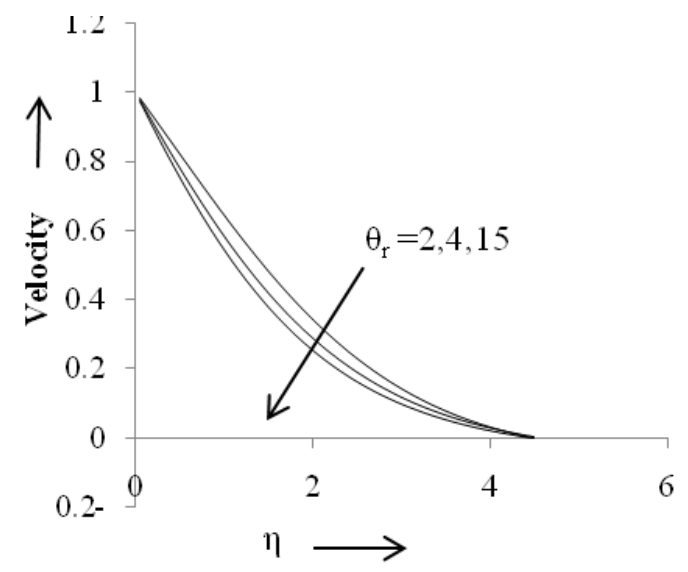

Fig. 2. Velocity profile with $\theta_{\mathrm{r}}$ for $\operatorname{Re}_{\mathrm{m}}=0.3, \operatorname{Pr}=0.1$, $\mathrm{Ec}=1, \mathrm{R}=1, \mathrm{Kc}=0.2, \tau=0.5, \mathrm{Sc}=0.5, \mathrm{n}=1$

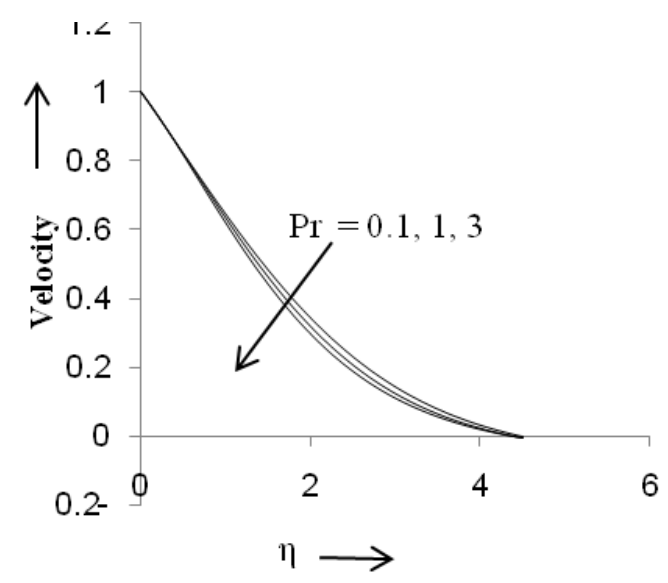

Fig. 3. Velocity profile with $\operatorname{Pr}$ for $\operatorname{Re}_{\mathrm{m}}=0.3, \mathrm{R}=1, \tau=$ $0.5, \mathrm{Sc}=0.5, \mathrm{Ec}=1, \mathrm{n}=1, \theta_{r}=2, \mathrm{Kc}=0.2$

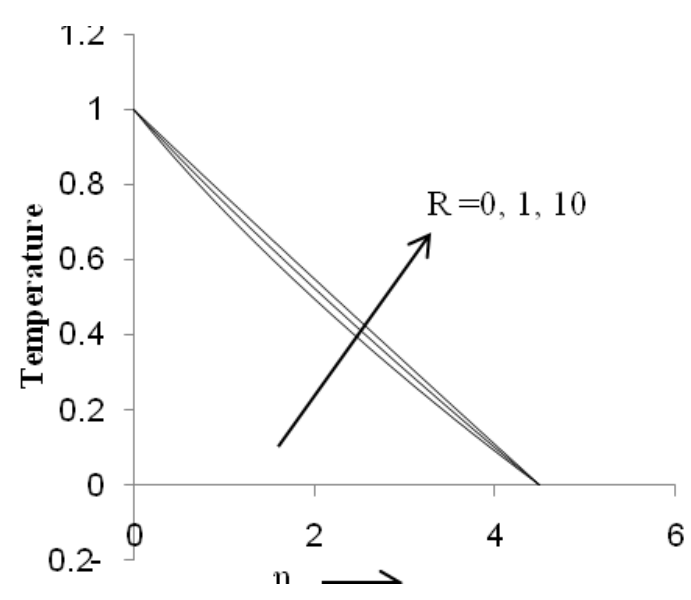

Fig. 4. Temperature profile with $\mathrm{R}$ for $\theta_{\mathrm{r}}=2, \mathrm{n}=1$, $\mathrm{Pr}=0.1, \mathrm{Ec}=1, \mathrm{R}=1, \mathrm{Kc}=0.2, \tau=0.5, \mathrm{Sc}=0.5, \mathrm{Re}_{\mathrm{m}}=0.3$

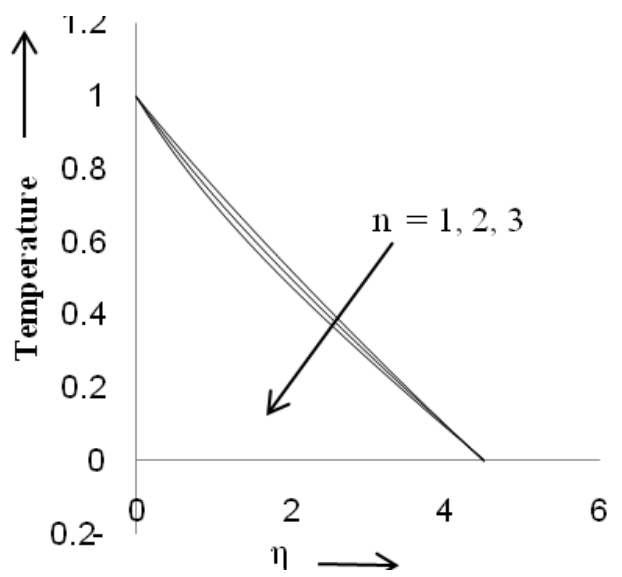

Fig. 5. Temperature profile with $\mathrm{n}$ for $\operatorname{Pr}=0.1, \mathrm{R}=1$, $\mathrm{Ec}=1, \mathrm{Kc}=0.2, \tau=0.5, \mathrm{Sc}=0.5, \mathrm{Re}_{\mathrm{m}}=0, \theta_{\mathrm{r}}=2$.

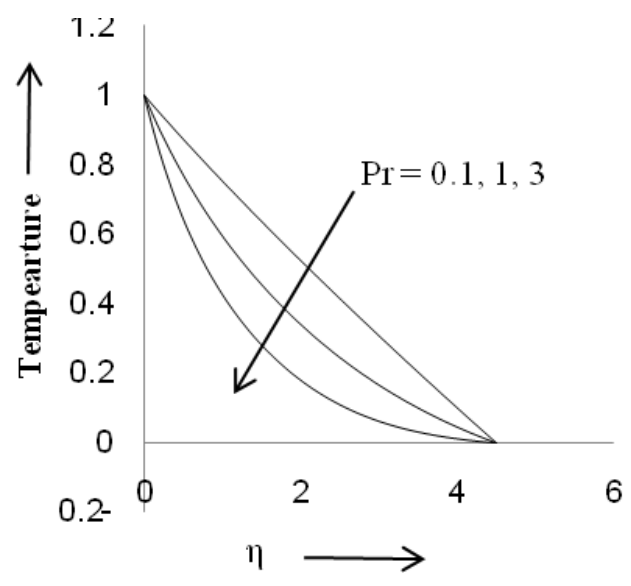

Fig. 6. Temperature profile with $\operatorname{Pr}$ for $\mathrm{Re}_{\mathrm{m}}=0.3, \mathrm{R}=1$, $\tau=0.5, \mathrm{Sc}=0.5, \mathrm{Ec}=1, \mathrm{n}=1, \theta_{\mathrm{r}}=2, \mathrm{Kc}=0.2$

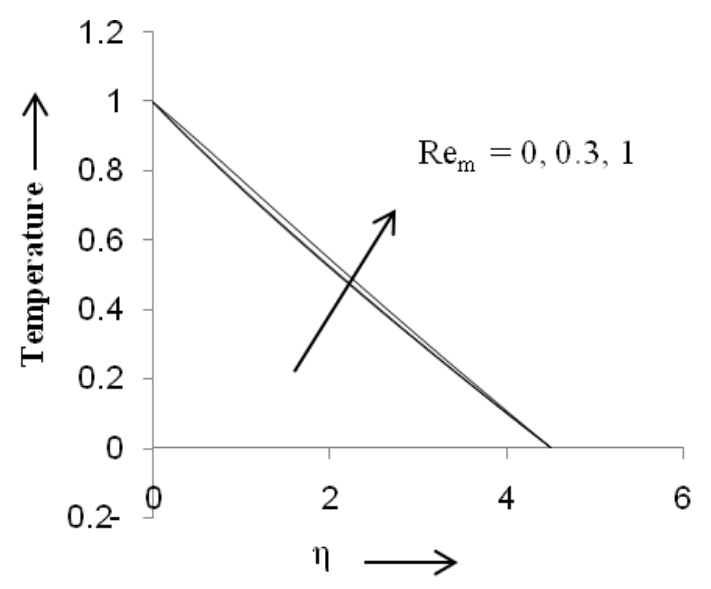

Fig. 7. Temperature profile with $\mathrm{Re}_{\mathrm{m}}$ for $\mathrm{R}=1, \mathrm{Pr}=0$, $\tau=0.5, \mathrm{Sc}=0.5, \mathrm{Ec}=1, \mathrm{n}=1, \theta_{\mathrm{r}}=2, \mathrm{Kc}=0.2$ 


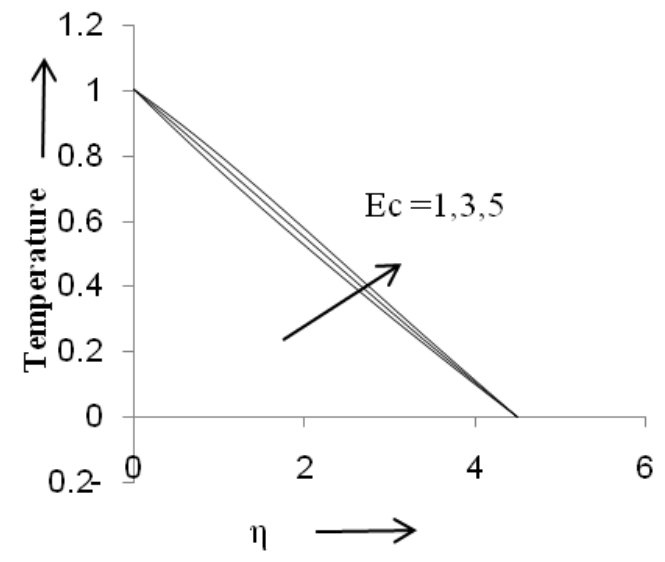

Fig. 8. Temperature profile with $E c$ for $\operatorname{Re}_{\mathrm{m}}=0.3, \mathrm{R}=1$, $\tau=0.5, \theta_{\mathrm{r}}=2, \mathrm{Kc}=0.2 \mathrm{Sc}=0.5, \mathrm{n}=1, \operatorname{Pr}=0.1$

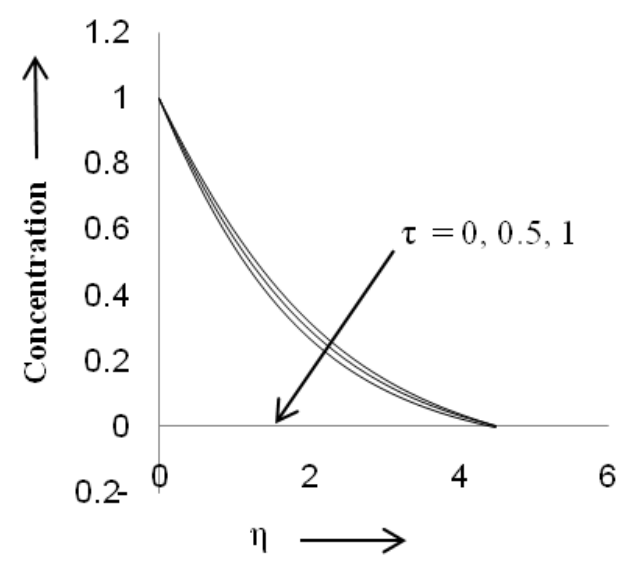

Fig. 9. Concentration profile with $\tau$ for $\mathrm{Re}_{\mathrm{m}}=0.3, \mathrm{R}=1$, $\theta_{\mathrm{r}}=2, \mathrm{Kc}=0.2, \mathrm{Sc}=0.5, \mathrm{n}=1, \mathrm{Pr}=0.1, \mathrm{Ec}=1$

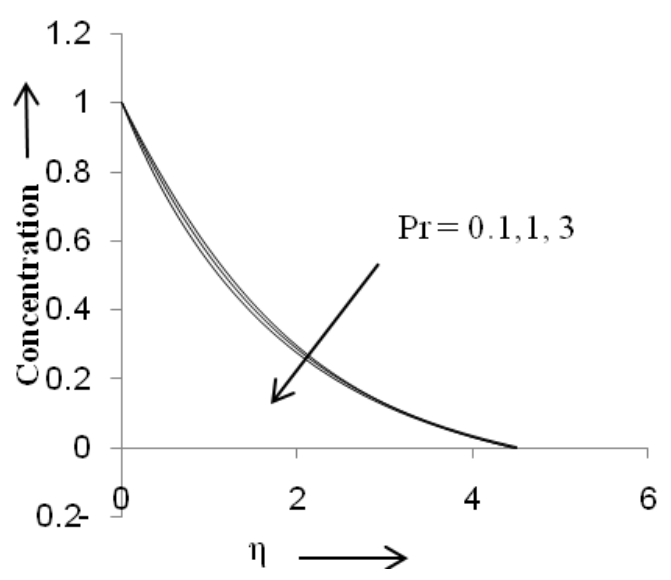

Fig. 10. Concentration profile with $\operatorname{Pr}$ for $\operatorname{Re}_{\mathrm{m}}=0.3$, $\tau=0.5, \mathrm{Sc}=0.5, \mathrm{Ec}=1, \mathrm{n}=1, \theta_{\mathrm{r}}=2, \mathrm{Kc}=0.2, \mathrm{R}=1$

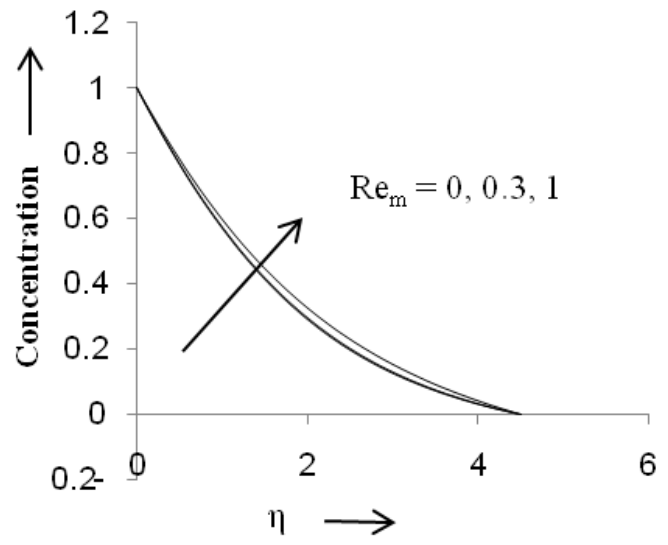

Fig. 11. Concentration profile with $\operatorname{Re}_{\mathrm{m}}$ for $\mathrm{Pr}=0.1$, $\tau=0.5, \mathrm{Sc}=0.5, \mathrm{Ec}=1, \mathrm{n}=1, \theta_{\mathrm{r}}=2, \mathrm{Kc}=0.2, \mathrm{R}=1$

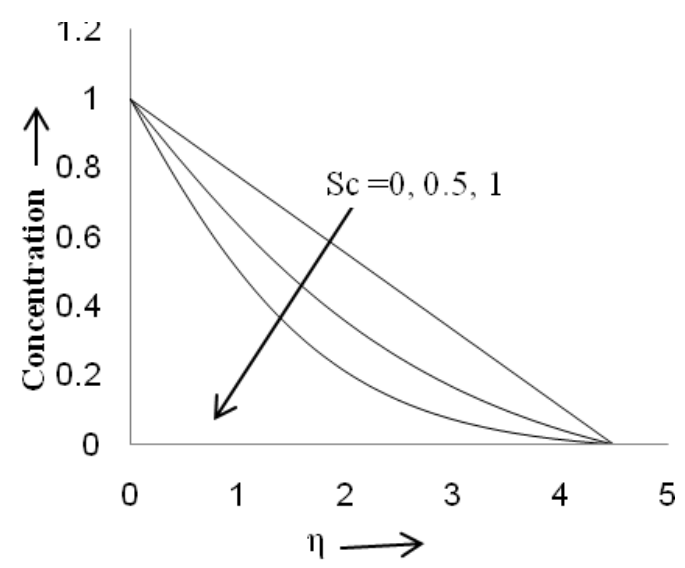

Fig. 12. Concentration profile with $\mathrm{Sc}$ for $\mathrm{Re}_{\mathrm{m}}=0.3$, $\mathrm{R}=1, \tau=0.5, \mathrm{Ec}=1, \mathrm{n}=1, \theta_{\mathrm{r}}=2, \mathrm{Kc}=0, \operatorname{Pr}=0.1$

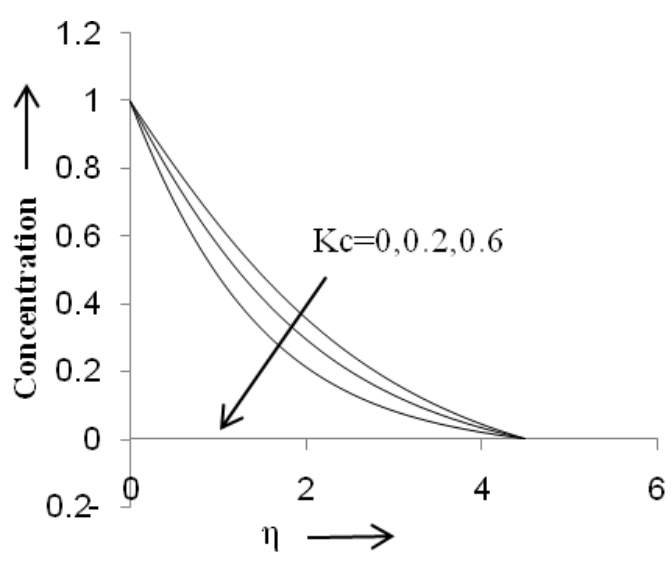

Fig. 13. Concentration profile with $\mathrm{Kc}$ for $\mathrm{Re}_{\mathrm{m}}=0.3$, $\mathrm{R}=1, \tau=0.5, \mathrm{Ec}=1, \mathrm{n}=1, \theta_{\mathrm{r}}=2, \operatorname{Pr}=0.1, \mathrm{Sc}=0.5$ 
B. Chandra et al. / JAFM, Vol. 6, No. 3, pp. 351- 356, 2013.

\section{REFERENCES}

Brewster, M.Q. (1992). Thermal Radiative Transfer and Properties, John Wiley and Sons, NewYork.

Erickson, L.E., Fan, L.T., and Fox,V.G. (1966). Heat and Mass transfer on moving continuous flat plate with suction or injection, Ind. Engg. Chem. Fundam.5, 19-25.

Fang,T.(2003). Similarity solutions for a moving flat plate thermal boundary layer, Acta Mech. 163, 161-172.

Howell,T.G., Jeng,D.R. and De Witt, K.J.(1997). Momentum and heat transfer on a continuous moving surface in a power law fluid, Int. J. Heat and Mass Transfer40, 1853-1861.

Jat, R.N. and Chaudhary, S. (2010).Hydromagnetic Flow and heat transfer on a continuously moving surface, Applied Mathematical Sciences 4(2),6578.

Kumari, M., and Nath, G. (2001). MHD boundary-layer flow of a non-Newtonian fluid over a continuously moving surface with a parallel free stream, Acta Mech. 146, 139-150.

Lai, F.C. and Kulacki, F.A.(1991) The effect of variable viscosity on convective heat and mass transfer along a vertical surface in saturated porous media, Int J Heat and Mass Transfer, 33, 1028-1031.
Makinde,O.D., A. Ogulu (2008), The effect of thermal radiation on the heat and mass transfer flow of a variable viscosity fluid past a vertical porous plate permeated by a transverse magnetic field, Chemical Engineering Communications 195(12), 1575-1584.

Pop, I., Gorla, R.S.R. and Rashidi, M. (1992).The effect of variable viscosity on flow and heat transfer to a continuously moving flat plate, Int. J. Eng Sci. $30,1-6$.

Sakiadis, B.C. (1961). Boundary layer behavior on continuous moving solid surfaces, AICHE, 7, 2628.

Schlichting, H. (1968) Boundary Layer Theory, McGraw-Hill Book Co., New York

Soundalgekar, V.M. and Murty,T.V. (1980) Heat transfer in flow past a continuous moving plate with variable temperature, Warme-und stoffubertrag-ung 14, 91-93.

Tsou, F.K., E.M. Sparrow, and R.J. Goldstein (1967) Flow and heat transfer in the boundary layer on a continuous moving surface, Int J Heat and Mass Transfer 10, 219-235. 